\section{Phone prompts to improve attendance at a new patient clinic}

\section{Dear Editor,}

Non-attendance by psychiatric outpatients has an important impact on clinical and economic outcomes. ${ }^{1}$ The national rate for non-attendance at all types of outpatient clinic in the UK has been reported as $12 \%{ }^{2}$, with rates varying depending on setting and specialty. ${ }^{3,4}$ Rates of non-attendance at psychiatric clinics are twice that of most other specialities. ${ }^{5,6}$ Many factors contribute to this finding including, stigma, lack of insight, inappropriate referral and lack of social stability.

It was against this background that we determined to tackle our non-attendance rates at a new patient clinic at Carrickmacross Day Care Centre. Given that the overwhelming majority of patients who attend our service are managed within the traditional outpatient setting it is of paramount importance that we avoid overlooking or neglecting this crucial arm of our services. Moreover, we had identified a marked nonattendance rate (48\%) for new patient appointments in the 12 months leading up to our pilot project. This added a sense of urgency to the exercise when one considers the cost in terms of loss of manpower time.

Having determined to address the non-attendance rate a search of the biomedical databases yielded numerous methods to improve attendance that we could choose from. Methods employed in the tackling of this problem included telephone prompting ${ }^{8}$ with or without specific visits to the home, ${ }^{9}$ financial incentives, ${ }^{10}$ issuing a copy of the referral letter to the appointee ${ }^{11}$ and text-based prompts. ${ }^{12}$ It was felt that phone prompts represented the most feasible option for our study.

\section{Methods}

A search of the biomedical databases was performed to identify methods of improving non-attendance. A letter was sent to the patient detailing the date, time and venue for their new patient appointment. This letter was copied to their GP. This is consistent with standard outpatient practice. Phone contact (landline or mobile depending on availability) was made with the patient to confirm the details. The standard referral forms to this service included the patient phone contact details. The nurse manager (T. MC) undertook responsibility for the phone contact and GP surgeries are usually contacted immediately if patients phone contacted are omitted to obtain the number. Phone calls were made one week before the appointment. The pilot project testing the impact of phone prompts on new patient attendance lasted twelve months. Rates of attendance were compared to rates for the equivalent period immediately prior to the initiative. Also rates were compared with rates of attendance for the equivalent period in the year after the initiative. (Phone prompts were continued.)

\section{Results}

In the 12 months prior to the pilot period there were 52 new patient appointments offered of which $48 \%$ (25) did not attend. During the pilot period there were 49 new patient appointments offered and only $20.4 \%$ (10) did not attend after they were all contacted on the phone. Of the 10 non-attendees during the pilot project, 30\% (3) had personality disorder, 20\% (2) anxiety disorder, 20\% (2) depressive illness, 20\% (2) PTSD (20\%) and postnatal depression 10\% (1). A year after the pilot, there was a further drop in the number of patients that did not turn up for their appointment. Some $11 \%$ (6) out of 53 new patient appointments offered did not turn up.

\section{Discussion}

First appointments at a mental health clinic can be a daunting prospect. ${ }^{12}$ In psychiatric services non-attendance gives rise to concern. Illnesses that erode insight and cause a downward spiral in quality of life have to be managed. ${ }^{13}$ Concern has been expressed that those most in need are the most difficult to engage. ${ }^{14}$ Further impetus is added to the need to tackle non-attendance when one considers that deterioration of mental state can result in risk of harm to the patient or others. ${ }^{15,16}$ It has been suggested that any effort to prompt attendance is likely to reduce the no show rate. ${ }^{17}$

Our finding of a $48 \%$ non-attendance rate in the 12 month period leading up to the plot period resembles the range of $26-50 \%$ reported previously for initial appointments. ${ }^{3,13}$ Nevertheless, the rate warrants action. The cost involved should not be underestimated. ${ }^{19}$ It has been highlighted that the cost of non-attendance to the NHS was $£ 300$ million annually in $1999^{20}$ and in 2009 this has increased to almost a billion pounds sterling a year. ${ }^{22}$ There is no equivalent data for the Irish health service.

Contact with the patient is not the only way to counteract non-attendance. Family input has been proposed as one mechanism that enables patients to seek care. ${ }^{22}$ Furthermore, ways of filtering the referral system including brief screening ${ }^{23}$ or liaison with $\mathrm{GPs}^{24}$ have been described. However, here we will focus on the impact of our phone prompt initiative.

As already mentioned, numerous methods of engaging the patient have been reported. ${ }^{8-12}$ The benefit accrued from prompts is not altogether clear and there are no guidelines to assist with respect to choosing which type of prompt should be employed..$^{25}$ Notwithstanding these concerns, we followed the recommendation of a Cochrane review ${ }^{13}$ that the introduction of a simple prompt merits local review. We opted for the phone contact because it enabled more direct, responsive and one could argue more human contact than sending a letter or texting. If the patient had any queries or reservations, phone contact provided an opportunity for discussion, explanation and reassurance. One of the authors (TMC) went through a set list of information including introducing himself, giving the time, date and venue for the appointment, directions to venue, likely duration of assessment and a brief explanation of the role of the psychiatrist. Another obvious and pragmatic aspect of our selected method of prompting was that it was inexpensive in terms of time and money.

Our results make interesting reading. Initially, we were very impressed that a phone call seemed to have more than halved our non-attendance rates for first appointments (rate fell from $48 \%$ to $20.4 \%$ ). It should be noted that all our new referrals were contacted and indicated that they would attend. We 
checked the rates of non-attendance for the corresponding period in the previous year and a year afterward when the prompt was continued. The rates for these periods were $48 \%$ and $11 \%$. Our annual figures indicate that we have a new patient referral rate of approximately one per week. Therefore, this makes it difficult to gather large numbers. It is possible that our phone prompts had the desired effect. However, more evidence is required.

It has been reported that the profile of mental disorder amongst new referrals for psychiatric outpatient assessment is significantly different from that of a follow-up population, with a predominance of non-psychotic disorder of lower severity ${ }^{5,26}$ Some evidence suggests that those with a diagnosis of personality disorder or a diagnosis from the neurotic, stress-related and somatoform spectrum are less likely to attend. ${ }^{27,}{ }^{28}$ Of the more serious diagnoses it has been noted that a variety of factors affecting attendance at psychiatric outpatient clinics come into play including active symptomatology such as paranoid delusions or feeling too depressed to get up, negative symptoms such as apathy and reduced organisational skills and a lack of insight. We had a total of 10 non-attendees. Our diagnoses were dependent on letter and phone contact with the GP (an obvious limitation). Thirty per cent (3) had either a diagnosis of personality disorder or history of overdoses with deliberate self-harm. Depressive illness 20\% (2), anxiety disorder 20\% (2) and post traumatic stress disorder $20 \%$ (2) accounted for $60 \%$ of the total referral. There was a single case of post-natal depression (1) made up the remaining $10 \%$. No statistically significant results emerged distinguishing between attendees and non-attendees.

Other factors which influence attendance at first appointment at psychiatric outpatient clinics could easily be overlooked. New referrals who do not agree to referral have been reported as less likely to attend. ${ }^{29,30}$ Clerical error has been shown to account for $45 \%$ of missed appointments in hospital specialities. ${ }^{31}$

Phone prompting is a cheap, easy and quick way of attempting to enhance attendance at the first appointment at a psychiatric out-patient clinic. With the advent of the mobile phone, one can almost guarantee contact with the appointee preserving patient confidentiality. Our study hints at a possible improved take-up of first assessments with the use of phone prompting. In other studies there has been a smaller time interval between phone call and clinic appointment ${ }^{13}$ (we rang I week beforehand, others have adhered to a ' 48 hour' beforehand rule). We, as already mentioned, chose to ring a week beforehand - we felt that it would enable us to offer the outpatient slot for another new patient should the patient indicate that they do not wish to attend. It is conceivable that the use of the other methods of prompting described could have an additive effect if used in conjunction with phone prompting. But there is no literature to support this hypothesis. No current evidence indicates that phone prompting has a negative effect on patient attendance.
In conclusion, we plan to continue this method of patient prompting. Further research should help to clarify, whether or not phone prompting has a beneficial effect on new patient attendance rates.

Adegboyega Osinowo, Senior Register, St Brigid's Hospital, Ardee, Co Louth. Thomas McEnteggart, Clinical Nurse Manager, Carrickmacross Day Centre, Co Monaghan. *MacDara McCauley, Consultant Psychiatrist, St Brigid's Hospital, Ardee, Co Louth, Ireland.

References

1. Mcivor $R$, Ek E, Carson J. Non-attendance rates patients attending different grades of psychiatrist and a clinical psychologist within a community mental health clinic. Psych Bull 2004; 28: 5-7.

2. Sharp $D$, Hamilton W. Non-attendance at general practices and outpatient clinics. BMJ 2001; 323: 1081-1082.

3. Chen A. Non-compliance in community psychiatry: a review of clinical considerations. Hos Comm. Psych 1991; 42: 282-287.

4. Gatrad AR. A completed audit to reduce hospitals non-attendance. Arch Dis Childhood 2000; 82: 59-61.

5. Killaspy $\mathrm{H}$ et al. Prospective controlled study of psychiatric out-patient non-attendance characteristics and outcome. B J Psych 2000; 176:160-165.

6 . McGlade KJ et al. Referrals to hospitals by general practitioners: a study of compliance and communication. BMJ 1988; 1246-48.

7. Hershom M. The elusive population: characteristics of attendees versus non-attendees for community mental centre intakes. Comm. Ment Health J 1193; 29(1):a9-57.

8. MacDonald J, Brown N, Ellis P. Using telephone prompts to improve initial attendance at a community mental health centre. Psych Ser $2000 ; 51(6): 812-4$.

9. Thi Pan T. Enhancing client adherence to psychotropic medication regiments: a psychosocial nursing approach. Int J Psych Nur Res 1995; 2(1): 147-72.

10. Guiffrida A, Torgerson D. Should we pay the patient? A review of financial incentives to enhance patient compliance. BMJ 1997; 315: 703-7.

11. Harmilton W, Round $A$, Sharp D. Effect on hospital attendance rates of giving patients a copy of their referral letter: a randomised controlled trial. BMJ 1999: 31B: 1392-1395.

12. Reda S, Makhoul S. Prompts to encourage appointment attendance for people with serious mental illness. Cochrane Library (2001), issue 1, oxford Update Software. 13. Mechanic D. In: Kastschnig H, Freeman H, Sartious N, editor(s). Quality of life in disorders. London: Wiley, 1997

14. Tyrer P, Coid J, Simmonds S, Joseph P, Marriot S. community mental health teams for people with severe mental illness and disordered personality. Cochrane Library (1999), issue 2, Oxford Update Software.

15. Ritchie JH, Dick $D$, Lingham $R$. The report of the inquiry into the care and treatment of Christopher Clunis. 1994 London. HMSO.

16. Steering Committee of the Confidential Inquiry into homicides and suicides by Mentally III People, 1996. Report of the Confidential Inquiry into homicides and suicides by Mentally III People. London. Royal College of Psychiatrists.

17. Kournay RF, Garber J, Tornusiciolo G. Improving the first appointment rates in child psychiatry outpatient clinics. J Am Acad Child Adol Psych 1990; 29(4): G57-60.

18. Kruse GR, Rohland $B M, W u X$. Factors associated with missed first appointments at a psychiatric clinic. Psych Serv 2002; 53(9): 1173-76.

19. Deitch R. Broken appointments: millions wasted? NHS Lancet 1984 i: 1419.

20. Stone CA, Palmer JH, Saxby PJ, Devaraj VS. Reducing non-attendance at outpatient clinics. J R Soc Med 1999; 92 114-18.

21. McGreevy R. No-shows draining resources, Irish Times health supplement. March 31,2009

22. Carpenter PJ, Morrow GR, Del Gaudio AC, et al. Who keeps the first outpatient appointment? Am J Psych 1981; 138:102-05.

23. Hamilton R, Gordon P, Naji S. Service innovation: the first year of a brief psychiatric screening clinic in primary care. Psych Bull 2002; 26:218-21.

24. Russell V, McCauley M, MacMahon J, et al. Liaison psychiatry in rural general practice. Ir J Psych Med 2003; 65-8.

25. Smoller J, Mclean R, Otto M, Pollack M. How do clinicians respond to patients that miss appointments? J Clin Psych 1998; 59(6): 330-8

26. Johnson DAW. An analysis of outpatient services. B J Psych 1973; 122:301-6.

27. Listet ES, Scott J. Did not attend: characteristics of patients who fail to attend their first appointment at a psychiatric out-patient clinic. Health Trends 1988; 20: 65-6.

28. Verbov J. Why 100 patients failed to keep an out-patient appointment-audit in a dermatology department. J R Soc Med, 1992; 85: 277-78

29. Koch A, Gillis LS. Non-attendance of psychiatric outpatients. S Afr Med J 1991 ; 80:289-91.

30. Grunebaum $M$, Luber $P$, Callahan $M$, et al. Predictors of missed appointments for psychiatric consultations in a primary care clinic. Psych Serv 1996; 47:848-52.

31. Potamitis T, Chell PB, Jones, et al, Non-attendance at ophthalmology out-patient clinics. J R Soc Med 1994; 87: 591-93. 

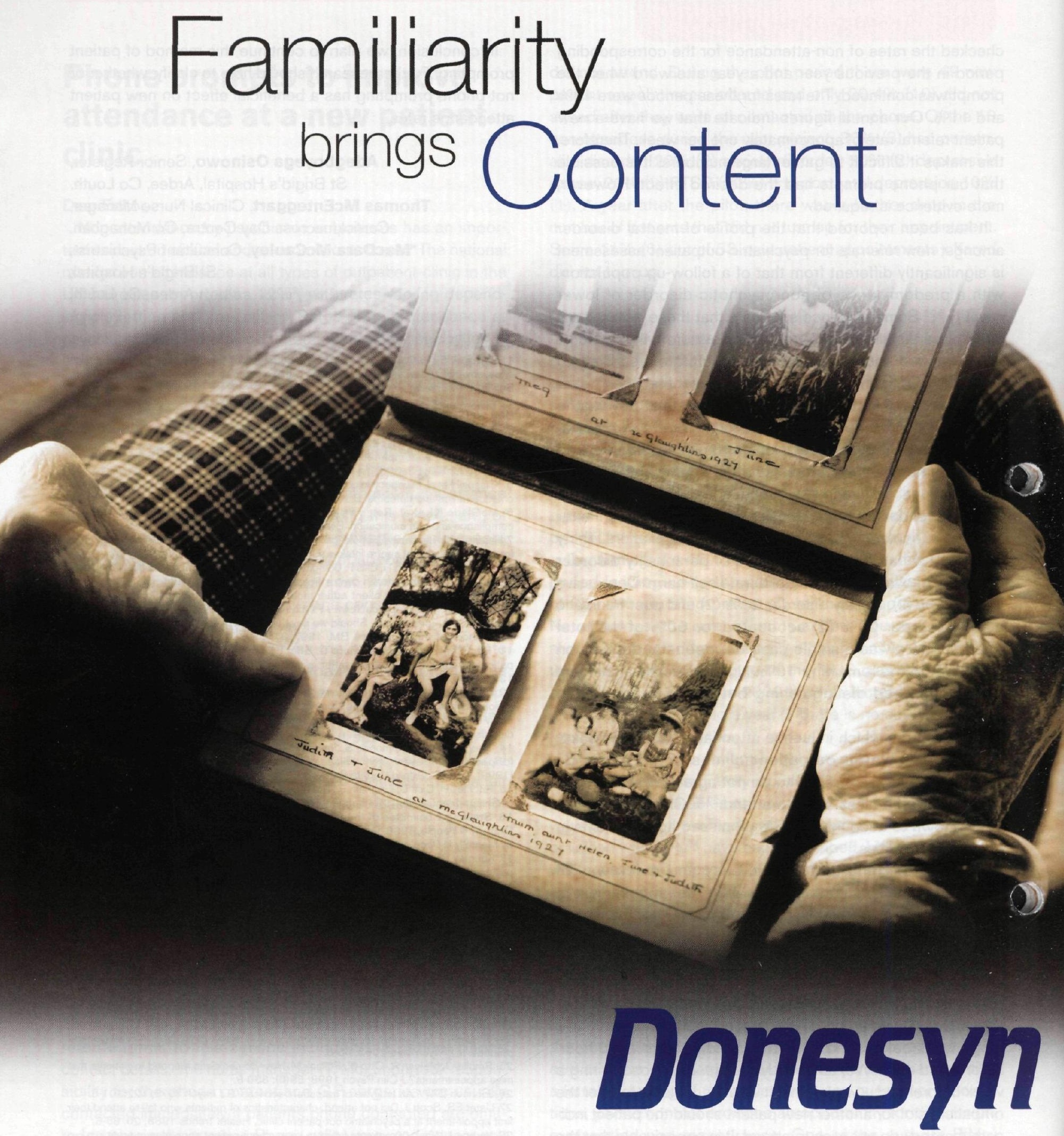

Mild to moderately severe Alzheimer's dementia. Donepezil 5, 10mg Tablets ABBREVIATED PRESCRIBING INFORMATION. Donesyn 5 and $10 \mathrm{mg}$ film-coated tablets 